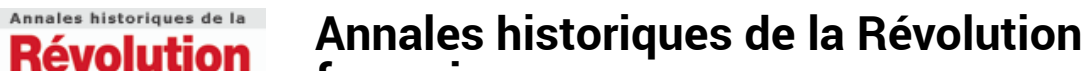 \\ française française
}

336 | avril-juin 2004

L'Espagne et Napoléon

\section{The Armies of Wellington}

\section{Charles Esdaile}

\section{(2) OpenEdition \\ Journals}

Édition électronique

URL : https://journals.openedition.org/ahrf/1747

DOI : $10.4000 /$ ahrf. 1747

ISSN : 1952-403X

\section{Éditeur :}

Armand Colin, Société des études robespierristes

\section{Édition imprimée}

Date de publication : 1 juin 2004

Pagination : 238

ISSN : 0003-4436

\section{Référence électronique}

Charles Esdaile, "The Armies of Wellington », Annales historiques de la Révolution française [En ligne], 336 | avril-juin 2004, mis en ligne le 20 février 2006, consulté le 23 avril 2022. URL : http:// journals.openedition.org/ahrf/1747 ; DOI : https://doi.org/10.4000/ahrf.1747

Ce document a été généré automatiquement le 23 avril 2022.

Tous droits réservés 


\title{
The Armies of Wellington
}

\author{
Charles Esdaile
}

\section{RÉFÉRENCE}

Phillip Haythornthwaite, The Armies of Wellington, Londres, Arms and Armour Press, 1998.

1 Pour des raisons diverses, l'armée de Wellington en Espagne n'a jamais cessé de fasciner les historiens anglais du fait militaire. Jamais vaincue par les Français, elle y gagna une extraordinaire réputation de courage, endura de terribles privations, joua un rôle clé dans l'éviction de l'Empire napoléonien hors d'Espagne et redora le crédit britannique sur la scène internationale. Aussi, ses actions (la marche de la division Light sur Fuentes des Oñoro, le siège de la brigade Hoghton à Albuera et l'attaque de Badajoz) sont considérées comme les faits d'armes les plus glorieux de tous ceux qui émaillent les trois cent cinquante ans d'histoire de l'armée britannique. Régulièrement, des auteurs ont cherché à produire une étude minutieuse du sujet. Phillip Haythornthwaite, écrivain bien connu du fait militaire, est le dernier en date parmi ceux-ci. Dans cet ouvrage, il nous propose une étude détaillée de la machine militaire qui a combattu en Espagne et au Portugal. Son approche est riche d'un travail de recherche fouillé. Le livre compte des chapitres sur le système militaire britannique, le corps des officiers, les hommes du rang, la vie quotidienne, l'infanterie, la cavalerie, l'artillerie, les troupes étrangères, le commissariat, les services médicaux, le haut commandement, l'expérience des combats et, finalement, les campagnes elles-mêmes. Quoiqu'elles ne donnent pas lieu à des traitements séparés, nombre d'autres entrées sont fournies par ces pages, notamment sur la paye, le recrutement et la discipline. Il y a, en fait, peu de sujets importants que l'auteur ait oublié. De surcroît, pour aider le lecteur dans sa démarche, il inclut un glossaire bienvenu des termes militaires et, encore plus intéressant, du sabir des soldats (qui sait encore aujourd'hui, par exemple, qu'un « ambassadeur du Maroc » était un cordonnier, un " article » une prostituée et «une puanteur»du pain?). Des regrets cependant: le sujet ayant été abordé auparavant, et de manière magistrale par Sir Charles Oman, il est peu vraisemblable 
que Les armées de Wellington puisse être considéré comme meilleure introduction à la connaissance des forces qui ont si bien servi Wellington. Quelle réponse donne le livre à la question des motivations de l'armée pour se battre avec tant de talent? Sur bien des points, la réponse est cruciale. Car, en théorie, l'armée britannique n'aurait pas dû briller autant face aux Français, non seulement parce que sa tactique et son organisation étaient surannées mais aussi parce qu'elle était largement recrutée parmi les déserteurs étrangers et - les mots sont de Wellington lui-même - «la lie de la terre", une société dans laquelle justice sociale et politique frappaient par leur absence. Les espoirs de promotion étaient faibles, la paye misérable, les hommes considérés comme des parias et soumis à un code de discipline sauvage usant de la flagellation. Pour Haythhornthwaite la réponse est simple. Pour pallier ses défaillances indubitables, l'armée britannique n'avait pas besoin des stimuli de l'idéologie politique ou d'un espoir de récompense: afin d'intéresser les hommes à une entreprise collective, mieux valait leur instiller le respect de leurs officiers et les rendre fiers de leur propre accomplissement. De ce point de vue, la «famille » d'accueil représentée par le régiment était fondamentale ; elle paraissait un point de ralliement inégalé dans aucune autre force militaire de l'époque. Peut-être est-ce aller trop loin mais l'idée de base est juste : pour battre la Révolution française et Napoléon, il n'était pas toujours nécessaire de reprendre leurs structures et leurs méthodes. 